\title{
REFORMA TRABALHISTA, TRABALHO COMO CONSTRUÇÃO DE CIDADANIA E NECESSIDADE DE PROTEÇÃO AOS DIREITOS FUNDAMENTAIS
}

\author{
Noemia Porto ${ }^{1}$ \\ Flávia Moreira Guimarães Pessoa ${ }^{2}$
}

Resumo. O presente artigo aborda aspecto da denominada de "Reforma Trabalhista", concernente à prevalência do negociado sobre o legislado, empreendendo análise crítica sobre a possibilidade de edição de normas negociais que não incrementem a condição social dos trabalhadores, sobretudo considerando o primado constitucional da dignidade e da cidadania.

Palavras-chaves. Reforma Trabalhista; negociado e legislado; dignidade; cidadania.

\section{LABOR REFORM, WORK AS A CONSTRUCTION OF CITIZENSHIP AND THE NEED FOR PROTECTION OF FUNDAMENTAL RIGHTS}

\begin{abstract}
This article addresses the aspect of the so-called "Labor Reform", concerning the prevalence of the negotiated over the legislated, undertaking a critical analysis on the possibility of publishing negotiating norms that do not increase the social condition of the workers, especially considering the constitutional primacy of dignity and of citizenship.
\end{abstract}

Keywords. Labor Reform; negotiated and legislated; dignity; citizenship.

\section{Introdução}

O presente artigo procura abordar a pretendida reforma trabalhista que enfoca a prevalência do negociado sobre o legislado, a partir de uma análise critica do trabalho como elemento de construção da cidadania e da necessidade de proteção ao hipossuficiente econômico.

O artigo é desenvolvido utilizando-se o método dedutivo a partir da análise do referencial teórico concretizador de Direitos Fundamentais na Condição Humana, especificamente no mundo do trabalho.

Para atingir o objetivo proposto, divide-se em três partes. Na primeira, analisa-se o trabalho como fator de construção da cidadania, considerando

1 Doutora em Direto, Estado e Constituição e Mestre em Direito, Estado e Constituição, pela Universidade de Brasília (UnB). Professora de Processo Constitucional da Faculdade Processus. Juíza do Trabalho do TRT/10 Região.

${ }^{2}$ Pós Doutora em Relações do Trabalho. Doutora em Direito Público. Professora do Mestrado em Direito da Universidade Federal de Sergipe e em Direitos Humanos da Universidade Tiradentes. Juíza do Trabalho do TRT/20a Região. 
principalmente o contributo filosófico de Hannah Arendt, com a distinção de trabalho, labor, contemplação e dignidade humana.

$\mathrm{Na}$ segunda parte, relaciona-se, criticamente, conceitos de trabalho digno, cidadania e o principio da proteção ao hipossuficente econômico, com o objetivo de criar o substrato teórico para a análise das reformas trabalhistas empreendidas na terceira parte do trabalho, especificamente no tocante à tentativa de prevalência do negociado sobre o legislado.

No terceiro item, analisa-se a pretensão de reforma trabalhista e suas conseqüências na construção da cidadania na sociedade brasileira, sustentando a necessidade de preservação dos direitos fundamentais.

Ao final são expostas as considerações conclusivas sobre o tema.

\section{O Trabalho como Fator de Construção da Cidadania}

O objetivo deste item é abordar como o trabalho atua na condição de elemento de posicionamento social do indivíduo e, nessa linha, de importante fator de construção de sua cidadania. A exclusão do mundo do trabalho representa, ao mesmo tempo, a exclusão de outros campos sociais - como o mercado, o sistema de ensino e a previdência. Pretende-se aqui problematizar as concepções de trabalho, dignidade e reconhecimento.

Hannah Arendt (1995, p. 89) lança a seguinte pergunta: em que consiste uma vida ativa? Confinada essa investigação na premissa de que "tudo gira em torno do trabalho", ou de que nossas vidas estão organizadas a partir de um eixo principal chamado trabalho, ainda que diversos cidadãos não possam e não consigam desenvolvê-lo, seria possível chegar a uma falsa constatação, qual seja, a de que a autora estivesse preocupada em delimitar quando é possível dizer que alguém é ativo ou quando não se está "parado", conforme linguagem comum utilizada pelos trabalhadores para referirem a ausência de ocupação.

Todavia, Arendt (1995, p. 89-90) lança um olhar para além desse confinamento que tem ocupado intensamente a vivência de cidadãos concretos, preocupados em morar, trabalhar, sobreviver, seguir em frente, distinguindo, ao menos inicialmente, os modos de vida entre contemplação e ação, a partir de como 


\section{Reforma trabalhista, trabalho como construção de cidadania e necessidade \\ de proteção aos direitos fundamentais}

essa distinção é considerada na construção do pensamento filosófico e religioso dos últimos séculos, justamente para pensar aspectos da modernidade.

Assim, pode-se compreender que a vida ativa não é somente aquela a que está consagrada a maioria dos homens, senão que também aquilo que nenhum homem pode escapar totalmente, ao menos no ciclo necessário para viver e sobreviver porque está na condição humana que a contemplação ${ }^{3}$ permaneça dependendo de todos os tipos de atividades; depende do labor que produz todo o necessário para manter vivo o organismo humano; depende do trabalho que cria todo o necessário para albergar o corpo humano; e necessita da ação a fim de organizar a vida em comum de muitos seres humanos de modo que a paz, a condição para a quietude da contemplação, esteja assegurada (ARENDT, 1995, p. 89- 90).

Refletindo sobre a época moderna, Hannah Arendt (1995, p. 91-92) refere a inversão por essa última produzida, qual seja, revela com traços fortes a glorificação do labor. A contemplação, então, se torna sem sentido. Além disso, não é habitual a distinção entre labor e trabalho (ARENDT, 1995, p. 92). A despeito disso, Arendt empreende análise etimológica e filosófica da diferença entre labor e trabalho. Notase que o labor se move sempre no mesmo ciclo dos organismos vivos e o final das suas fadigas e problemas apenas se dá com o fim, é dizer, com a morte do organismo individual (ARENDT, 1995, p. 93-94). O labor carrega o signo da necessidade, da necessidade de subsistir, pela eterna imposição feita pela natureza (ARENDT, 1995, p. 94). O labor, assim, acaba quando acabam as necessidades físicas.

É necessário lidar, porém, com uma perspectiva nova que se apresenta, ou seja, a produção de bens de consumo para além da necessidade de quem labora e de sua família (ARENDT, 1995, p. 95). A abundância natural do processo de labor tem permitido aos homens escravizarem e explorarem seus semelhantes, liberando a si mesmos, desta maneira, da carga da vida; e apesar de essa liberação de alguns ter sido sempre lograda por meio da força de uma classe dirigente, não teria sido nunca

A autora desenvolve o raciocínio demonstrando que tradicionalmente a vida ativa toma o significado da vida contemplativa; a ação serve às necessidades da contemplação. Além disso, até certo período, é possível afirmar a superioridade da contemplação, como modo de vida dos filósofos, em contraponto ao modo de vida do cidadão na pólis (ARENDT, 1995, p. 90). 
possível sem esta fertilidade inerente ao próprio labor humano (ARENDT, 1995, p. 95).

Nessa linha, Jessé Souza (2010, p. 26) assinala:

(...) o capitalismo moderno é habitado por uma irracionalidade fundamental: é a primeira forma de produção econômica na história que está desvinculada de uma relação direta com necessidades humanas, ou com "valores de uso", como diria Karl Marx. A definição mais abstrata de capitalismo envolve a ideia de uma acumulação ilimitada de capital como um fim em si mesmo (2010, p. 26).

O labor participa da própria condição da vida e como tal da fadiga e dos problemas da existência, mas também das condições de satisfação e de felicidade (ARENDT, 1995, p. 95). Evidentemente que a miséria, o esgotamento e a desgraça quebram o equilíbrio da ideia de labor.

Arendt exercita reflexões críticas que pretendem laçar luzes sobre a (não) condição humana quando fala do labor, do trabalho e da ação e, nesse sentido, adverte que o produto final tem organizado o próprio processo de trabalho, decidindo os especialistas necessários, a medida de cooperação e o número de participantes ou de operadores. Daí que tudo e todos são julgados em termos da sua utilidade e adequação ao produto final desejado e nada mais (ARENDT, 1995, p. 100). Nessa linha, Arendt critica o que chama de utilitarismo. Em outras palavras, em um mundo estritamente utilitário, todos os fins estão forçados a ter uma curta duração; são transformados em meios para fins ulteriores. Uma vez logrado, o fim cessa de ser um fim e se converte em um objeto entre objetos que a qualquer momento podem ser transformados em meios para lograr outros fins.

De certa maneira, esta advertência também está presente nos alertas que Caillé (1998) faz em relação ao utilitarismo. A perplexidade do utilitarismo que constitui, por assim dizer, a filosofia do Homo Faber, é que termina por ficar preso a uma interminável cadeia de meios e fins sem definir nunca um princípio que possa justificar a respectiva categoria, vale dizer, a utilidade mesma (ARENDT, 1995, p. $101)$.

Trata-se de um ciclo em que o que se pode definir como dignidade - que na visão de Margalit (2001) é diverso de estabelecer para os homens a função de números para estatísticas ou de serem vistos como instrumentos para um fim qualquer 
- se perde ou se deteriora. De maneira acertada, Hannah Arendt destaca que o que está em jogo não é a instrumentalidade como tal, o uso de meios para lograr um fim, senão que a generalização da experiência da fabricação onde o proveito e a utilidade são estabelecidos como as normas últimas para o mundo, assim como para a vida ativa dos homens que se movem (1995, p. 101-102).

Que ação seria possível, ou que vida ativa, cidadã, numa perspectiva mais abrangente, é viável, e com quais espaços e possibilidades, quando os esforços humanos ficam direcionados predominantemente ao ato de trabalhar, de manter-se trabalhando, de conseguir trabalho, de mudar de trabalho, de "evoluir" no trabalho, de ser útil? Pensando nas necessidades criadas e estabelecidas que aliam trabalho e vivência social, quais possibilidades têm os trabalhadores de resistirem à ideia de que para o trabalho é necessário um envolvimento constante com a atividade que se pretende desenvolver, que passa, então, a adquirir um valor em si mesmo? Nestes termos, o presente item buscou questionar o valor do trabalho humano para a construção da cidadania, com o objetivo de relacionar o tema, no tópico seguinte, com a tutela jurídica protecionista trabalhista.

\section{O Trabalho digno e o Princípio da Proteção ao Hipossuficiente Econômico}

Há no Brasil uma implicação articulada entre o não-reconhecimento da dignidade e a negação de direitos básicos aos cidadãos. Respeito e consideração não se relacionam com o reconhecimento do mérito ou da aptidão de uma pessoa, mas com a sua condição humana, que, por essa razão, deveria designar o respeito a direitos universalizáveis. A compreensão da nossa própria condição humana implica perceber a humanidade no outro (MARGALIT, 2001, p. 135).

Para Geertz:

Ver-nos como os outros nos veem pode ser bastante esclarecedor. Acreditar que outros possuem a mesma natureza que possuímos é o mínimo que se espera de uma pessoa decente. A largueza de espírito, no entanto, sem a qual a objetividade é nada mais que autocongratulação, e a tolerância apenas hipocrisia, surge através de uma conquista muito mais difícil: a de ver-nos, entre outros, como apenas mais um exemplo da forma que a vida humana adotou em um determinado lugar, um caso entre casos, um mundo entre mundos. Se a antropologia interpretativa tem alguma função geral no mundo, é a de constantemente reensinar esta verdade fugaz (2012, p. 22). 
Uma questão interessante colocada por Avishai Margalit (2001, p. 139), após as análises sobre a temática do reconhecimento em Hegel e Honneth (com ênfase nos três estágios de reconhecimento: amor, respeito aos direitos e solidariedade ou autoestima), seria a de como passar daquilo que ele chama de uma espessura de relacionamento "tribal" para uma etapa de reconhecimento dos direitos formais de pessoas que são estranhas para nós. Afinal, a dignidade carrega o sentido da alteridade na projeção sociopolítica.

Para Cardoso de Oliveira:

a grande dificuldade para dar uma resposta satisfatória às demandas
por reconhecimento é que estas não podem ser inteiramente
contempladas quando se fica exclusivamente no plano formal ou da
linguagem dos direitos legais. Tais demandas requerem, além disso,
uma aceitação substantiva do valor ou mérito da identidade em
pauta. Isto é, um ato de reconhecimento não pode se sustentar como
tal apenas no nível do comportamento ou da aplicação da lei, mas
deve ser capaz de transmitir ou expressar uma atitude de
consideração. Na mesma direção, se é difícil exigir tal atitude como
um direito legal, não é tão difícil concebê-la como uma obrigação
moral. É nesse sentido que entendo a observação de Taylor de que
as demandas por reconhecimento requerem a existência de relaçães
dialógicas entre as partes (Taylor, 1994), as quais se levam a sério e
manifestam reciprocamente a aceitação da posição ou status de
igualdade como uma condição merecida e mutuamente
compartilhada (2011, p. 180).

A relação humana é mediada pelo outro. Essa mediação possibilita um processo de autoconhecimento. "Enquanto a interação humana não é percebida como envolvendo uma clivagem entre o 'eu' e o 'outro', nem a existência nem o lugar do sujeito são capazes de levantar quaisquer problemas significativos (ROSENFELD, 2003, p. 29). Em suma, é fundamental o ponto de vista do outro (MARGALIT, 2001).

Para a compreensão dessa temática, é relevante estabelecer um traço distintivo entre um sistema de tutela das pessoas e um sistema de tutela dos direitos. A dogmática trabalhista quando afirma o traço tutelar do direito do trabalho, a partir da ideia da hipossuficiência do trabalhador, parece caminhar no sentido de que seria importante promover a tutela das pessoas trabalhadoras (e empregadas). Pensando numa perspectiva democrática de direito, o respeito e a consideração devidos a cada pessoa, independentemente da relação contratual que protagonize e que, portanto, não pode ser vista como alguém débil ou incapaz de expressar suas próprias demandas e 
reclamos, exigiria uma postura jurídica que levasse a sério os próprios trabalhadores, não confundindo a tutela a direitos com a tutela à pessoa, justamente porque essa última tende a inferiorizar o indivíduo, sem promover sua esfera importante de autonomia. A percepção do trabalhador como alguém débil na relação contratual pode, inclusive, servir de barreira à construção de um ambiente laboral democrático em que seja percebido como um ator e um articulador importante para o desenvolvimento do próprio trabalho. Evidentemente, na perspectiva de uma tutela dos direitos, os direitos devem visar às pessoas, de forma universalizante.

É importante o alerta feito por Menelick de Carvalho Netto:

Para Rosenfeld, tal como para Friedrich Müller, Chantal Mouffe e a maior parte da filosofia política e da doutrina constitucional atuais, sabemos hoje, por experiência própria, que a tutela paternalista elimina precisamente o que ela afirma preservar. Ela subtrai dos cidadãos exatamente a cidadania, o respeito à sua capacidade de autonomia, à sua capacidade de aprender com os próprios erros, preservando eternamente a minoridade de um povo reduzido à condição de massa (de uma não- cidadania), manipulável e instrumentalizada por parte daqueles que se apresentam como os seus tutores, como os seus defensores, mas que, ainda que de modo inconsciente, crêem a priori e autoritariamente na sua superioridade em relação aos demais e, assim, os desqualificam como possíveis interlocutores. O debate público e os processos constitucionais de formação de uma ampla vontade e opinião públicas são assim privatizados (2003b, p. 11).

Os riscos que aparecem nos estudos de Menelick de Carvalho Netto (2003a; 2003b) também encontram expressão nas preocupações da antropologia jurídica:

... a tutela de direitos, no Brasil, se transforma em tutela de pessoas, não capazes aos olhos dos operadores de decidir sobre seus próprios direitos ou de resolver o que é melhor para suas vidas e para suas famílias. A doutrina jurídica costuma se referir à tutela de direitos pela lei e consequentemente sua garantia pela força do Estado. Tutelados pela lei são os direitos e, por isso, garantidos pelo Estado - cidadãos - fortes ou fracos - são seus titulares e por isto devem têlos garantidos pelo Estado. Entre nós, todavia, essas noções se atualizam com base na nossa forma peculiar de ver a igualdade jurídica, segundo a qual o Estado deve tratar desigualmente os desiguais. Assim, os cidadãos ditos 'mais fracos' são vistos pelo mundo jurídico como seres tuteláveis, incapazes, a terem suas vontades minimizadas e substituídas pela vontade do agente do Estado, daí a ideia de hipossuficiência (FIGUEIRA \& MENDES, 2014, p. 525). 
Mas, afinal de contas, em que medida o trabalho é importante para os direitos de cidadania? O trabalho atua como um importante fator da cidadania e o processo de sua ressignificação evidencia que está em curso, ao mesmo tempo, também um processo de ressignificação da própria cidadania. Porém, como o direito do trabalho, informado pelo princípio normativo de proteção, incorpora, trabalha e retrabalha a noção de cidadania?

O princípio normativo da proteção que rege e procura conferir coerência interna ao Direito do Trabalho, envolve pensar a ideia de hipossuficiência. Na realidade, tanto o alcance do significado da proteção, como a justificativa da hipossuficiência, precisam ser explorados à luz das concepções de igualdade, cidadania e dignidade que são construídas de forma plural pelos próprios trabalhadores, a partir de situações concretas de vida. Figueira e Mendes (2014) destacam a importância de se investigar os sentidos da categoria hipossuficiência no discurso jurídico brasileiro, cumprindo mencionar desde logo que ela não goza da mesma significação entre os juristas trabalhistas ou os profissionais especializados na área, ou entre uns e outros. Os mesmos autores acima mencionados, falando dos manuais de Direito do Trabalho e da legislação trabalhista, destacam que o conhecido princípio da proteção "é categoria nativa desse campo e sugere que a interpretação e o julgamento dos conflitos trabalhistas deve ter em conta que o trabalhador é a parte 'mais fraca' no litígio" (2014, p. 523). O que os autores propõem, a partir dessa constatação, é refletir sobre o percurso que conduziu, no plano trabalhista, à categoria hipossuficiência.

Fazendo uma análise sobre a clássica doutrina trabalhista, a partir do discurso referencial do jurista Evaristo de Moraes, os autores constatam que tal doutrinador “justifica e preconiza a interferência do Estado pela via legislativa para, desigualando juridicamente, igualar socialmente, em um mecanismo claramente compensatório das desigualdades materiais próprias das economias de mercado" (FIGUEIRA \& MENDES, 2014, p. 530). Na mesma linha, desta vez explorando a doutrina também clássica presente nos estudos do professor Luiz de Pinho Pedreira Silva, os autores mencionam a definição do princípio protetivo, em razão do qual se reconhece a desigualdade de fato entre sujeitos da relação jurídica de trabalho e se procura promover a atenuação da inferioridade econômica, hierárquica e intelectual dos trabalhadores (FIGUEIRA \& MENDES, 2014, p. 531). Outro jurista conhecido no 
campo do Direito do Trabalho tem seu pensamento referido. Trata-se de Arnaldo Süssekind que sustenta, na percepção dos autores, que o princípio da proteção do trabalhador é resultante da imperatividade do direito do trabalho, pois a intervenção do Estado nas relações de trabalho estabelece uma ordem pública limitadora da autonomia da vontade. (FIGUEIRA \& MENDES, 2014, p. 532).

Desse modo, o discurso jurídico da hipossuficiência aparece, nesse contexto, como justificador da necessidade de proteção ao trabalhador por parte do Estado, em razão da assimetria de poder nas relações entre empregados e empregadores. A igualdade jurídica, tal como é atualizada na cultura jurídica brasileira, deve ser interpretada e aplicada pelos agentes do Estado tutelar como uma função compensatória das desigualdades econômicas e sociais (2014, p. 535).

As muitas reflexões que tais assertivas comportam conduzem, no mínimo, à constatação de que não se trata de uma equação simples, essa que se propõe a refletir criticamente sobre os dilemas da igualdade e da cidadania, a partir do eixo trabalho. Assumindo-se a complexidade implicada, não parece trazer grande contribuição para o debate sobre as situações de insulto experimentadas e vivenciadas de maneira variável, móvel, mas constante, pelos trabalhadores, especialmente no caso das periferias brasileiras, um diálogo que confine os problemas do mundo do trabalho ao contraponto entre neoliberalismo e justiça social. Até porque a semântica e a prática em torno dessas adjetivações são equívocas e comportam vivências concretas das mais variadas. Nessa mesma linha, contrapor individualismo e solidariedade, ou direitos individuais e direitos sociais e coletivos, não consegue transformar demandas por respeito em efetivo cumprimento dos direitos universalizáveis dos cidadãos.

É nesse contexto de complexidade que deve se inserir a análise das propostas de prevalência do negociado sobre o legislado, em tramitação no congresso nacional, que será objeto de análise no tópico seguinte.

\section{O Princípio da Proteção e a Proposta de Prevalência do Negociado sobre o}

\section{Legislado - o Desafio da Proteção aos Direitos Fundamentais}

Recentemente, temos acompanhado um cenário de crise política e econômica enfrentados pelo país e que tem gerado reflexo nos mais diversos setores e classes. Exemplos disso são os projetos para a Reforma da legislação Trabalhista. Dentre as 
inúmeras propostas destinadas à desregulamentação da legislação trabalhista, podemos citar a prevalência do negociado sobre o legislado (PL 4.962/2016), além do PL 6.797/2016, o qual pretende alterar importantes artigos da CLT.

Analisando tais projetos, Guilherme Guimarães Feliciano (2017) entende que é papel do Direito do Trabalho e da Justiça do Trabalho evitar que ocorram retrocessos sociais, devendo ser esta perspectiva seguida pelo Brasil, país que convive com o paradoxo de uma Constituição consagradora dos direitos sociais, como direitos fundamentais $\left(\operatorname{art} .7^{\circ}\right.$ ), por um lado, mas, por outro, com uma sociedade extremamente desigual, cujos titulares do poder (político e econômico) resistem em efetivar essa mesma Constituição, insistindo em torná-la apenas programática e enunciativa.

Verifica-se no Brasil que a regra da unicidade construiu uma estrutura sindical frágil, pouco representativa e bastante rígida (art. $8^{\circ}$, inciso II e IV da $\mathrm{CF} / 88$ ). E, apesar dessa unicidade, o Brasil conta com mais de 15.000 sindicatos, muitos dos quais foram criados apenas para arrecadar a contribuição sindical e pouco ou nadam contribuem para uma discussão, a sério, sobre a melhoria da condição de vida dos trabalhadores. A despeito dos avanços de 1988, não se trilhou o caminho em direção a uma liberdade sindical plena, que implicaria considerar que os próprios trabalhadores é que devem decidir o modelo da organização coletiva, sem amarras na unicidade ou na contribuição sindical compulsória.

A participação dos trabalhadores (individual e coletivamente) ocorre através dos sindicatos ou das entidades sindicais que abrangem, no Brasil, todas as representações inclusas no nosso modelo sindical, quais sejam: as centrais sindicais (desprovidas do poder de negociação direta com as categorias patronais), as confederações (formadas por no mínimo três federações), as federações (formadas por ao menos cinco sindicatos), além dos sindicatos propriamente ditos. Esta participação pode ocorrer por meio da negociação coletiva ou através da pressão, a exemplo da autotutela coletiva da greve.

As definições sobre flexibilização comportam diversos aspectos, dentre eles, sociais, jurídicos, econômicos e até políticos. O conceito de flexibilização está estreitamente ligado ao de desregulamentação, uma vez que esta representa uma espécie de flexibilização feita através da legislação. A flexibilização atuaria na possibilidade de negociação de direitos legalmente previstos pela simples atuação sindical. 
Assim, no Direito do Trabalho, a flexibilização representa o conjunto de medidas destinadas a adaptar, reduzir ou eliminar direitos trabalhistas conforme a realidade econômica e produtiva enfrentada. Também é vista como um instrumento de política social capaz de adequar as normas jurídicas à realidade econômica, social e institucional.

Maurício Godinho Delgado salienta:

Por flexibilização trabalhista, entende-se a possibilidade jurídica, estipulada por norma estatal ou por norma coletiva negociada, de atenuação da força imperativa ou das normas componentes do Direito do Trabalho, de modo a mitigar a amplitude de seus comandos e/ou parâmetros próprios para a sua incidência (DELGADO, 2016, p. 67).

Nesse contexto, as propostas de reforma flexibilizadora trabalhistas tem como suposta a pretensão de retomada do crescimento econômico e a atualização das normas que regulam as relações de trabalho, mas sem contemplarem uma discussão sobre o fortalecimento da proteção que possa conferir aos trabalhadores melhorias efetivas nas respectivas condições de vida.

É importante destacar, no entanto, que a ideia segundo a qual a proteção trabalhista pode barrar crescimento econômico é uma falácia, pois o custo do trabalho no Brasil já é extremamente reduzido, sendo cerca de dez vezes menor que na Austrália, por exemplo. No Brasil, o salário mínimo/hora é de cerca de $\mathrm{R} \$ 4,00$, isso em relação aos EUA ( $\mathrm{R}$ \$ 23), Alemanha ( $\mathrm{R}$ \$ 25), Espanha (R\$ 17) e Portugal (R\$ 15), e, comparando com os países vizinhos, temos o Chile (R\$6,00) (TRINDADE, 2017).

Embora se repita, com razoável constância, que uma reforma trabalhista que prestigiasse a negociação coletiva, possibilitando que essa última possa reduzir direitos previstos legalmente, seria a solução para a redução de custos do trabalho, essa constatação não está baseada em estudos consistentes. Não bastasse isso, de todo modo, o custo econômico não pode ser fator que autonomamente possa designar a fragilização do sistema normativo jurídico de proteção às pessoas, sobretudo daquelas que necessitam viver do seu trabalho.

Na mesma linha de raciocínio, a Organização Internacional do Trabalho (OIT) e a Organização de Cooperação e Desenvolvimento Econômico (OCDE) apresentaram estudos que apontam não haver correlação entre a flexibilização 
trabalhista e a geração de empregos. Em verdade, o que ocorre é o oposto, pois, é justamente a proteção do trabalho que assegura melhor distribuição de renda e permite que a economia se mantenha em alta (TRINDADE, 2017), o que inclui as esferas do consumo, do estudo e da previdência, para ficar apenas em alguns.

Aliados a isto, estudos semelhantes apontam que a ampliação da jornada de trabalho é desvantajosa para todos, pois reduzem os postos de trabalho, fazem crescer o número de acidentes e ampliam as faltas ao serviço. Tudo isso sobrecarrega a sociedade, especialmente com pagamento de benefícios previdenciários. Um exemplo disso é a Suécia, que após limitar sua jornada semanal de trabalho, observou um aumento na produtividade, acompanhada de redução das faltas e doenças relacionadas ao trabalho, experiência essa que contraria e desmistifica as asserções de alguns economistas (TRINDADE, 2017).

Deste modo, torna-se sem efeito o discurso de que é preciso reduzir os direitos trabalhistas devido à rigidez de sua legislação, bem como o alto custo para a produção, como forma de alavancar a economia.

Mais complicado ainda seria considerar a possibilidade de flexibilização dessa suposta rigidez através de uma prevalência total da negociação coletiva, sem nenhuma discussão antecedente e séria sobre o modelo do sindicalismo brasileiro. Seria o mesmo de ver no sindicalismo atual um meio utilitário para o fim da redução de direitos.

Outra justificativa para a açodada reforma está relacionada com o excesso de processos trabalhistas, uma vez que a Justiça do Trabalho conta com milhões de ações, um número realmente assustador. Contudo, a abundância de processos está longe de ser um problema único das relações trabalhistas, pois, ao analisarmos o sistema nacional de justiça como um todo, percebemos que a Justiça do Trabalho e a Justiça Federal têm praticamente o mesmo percentual, entre o total de processos no país, cada uma com, aproximadamente, 14\% (TRINDADE, 2017). A grande campeã é a Justiça Estadual, com seus $70 \%$ de novos casos. Ora, mas também não tinha como ser diferente, já que somos um país de descumpridores da lei e fazemos de conta que ela não existe até que o poder judiciário determine o seu cumprimento (TRINDADE, 2017). Portanto, se há uma "crise de "judicialidade" ou um "excesso de judicialização", certamente suas razões, complexas e multifacetadas, não têm relação direta com as normas de proteção às pessoas trabalhadoras; um desses fatores 
possíveis certamente são as demandas, legítimas, dos cidadãos para que haja respeito aos direitos constitucionalmente estabelecidos.

Desta forma, o que se pode verificar é que o açodamento na condução das reformas trabalhistas no Congresso Nacional não contribuirá para a solução do tão relevante tema relacionado à contraposição do negociado com o legislado, e tampouco para o dilema constitucional do alcance e do significado da proteção como mote para a prevalência da dignidade da pessoa trabalhadora.

Com efeito, a matéria pertinente à prevalência da negociação coletiva é objeto de lenta abordagem jurisprudencial, tratando-se de tema ventilado em alguns casos paradigmáticos no Supremo Tribunal Federal.

Inicialmente, tem-se o Recurso Extraordinário no 590.415/SC, cuja relatoria foi do Ministro Luís Roberto Barroso, que reconheceu como válida a cláusula que oferece quitação ampla e irrestrita de todas as parcelas provenientes do contrato de trabalho no Plano de Dispensa Incentivada:

Direito do Trabalho. Acordo coletivo. Plano de dispensa incentivada. Validade e efeitos. 1. Plano de dispensa incentivada aprovado em acordo coletivo que contou com ampla participação dos empregados. Previsão de vantagens aos trabalhadores, bem como quitação de toda e qualquer parcela decorrente de relação de emprego. Faculdade do empregado de optar ou não pelo plano. 2. Validade da quitação ampla. Não incidência, na hipótese, do art. 477, § $2^{\circ}$ da Consolidação das Leis do Trabalho, que restringe a eficácia liberatória da quitação aos valores e às parcelas discriminadas no termo de rescisão exclusivamente. 3. No âmbito do direito coletivo do trabalho não se verifica a mesma situação de assimetria de poder presente nas relações individuais de trabalho. Como consequência, a autonomia coletiva da vontade não se encontra sujeita aos mesmos limites que a autonomia individual. 4. A Constituição de 1988, em seu artigo $7^{\circ}$, XXVI, prestigiou a autonomia coletiva da vontade e a autocomposição dos conflitos trabalhistas, acompanhando a tendência mundial ao crescente reconhecimento dos mecanismos de negociação coletiva, retratada na Convenção n. 98/1949 e na Convenção n. 154/1981 da Organização Internacional do Trabalho. O reconhecimento dos acordos e convenções coletivas permite que os trabalhadores contribuam para a formulação das normas que regerão a sua própria vida. 5. Os planos de dispensa incentivada permitem reduzir as repercussões sociais das dispensas, assegurando àqueles que optam por seu desligamento da empresa condições econômicas mais vantajosas do que aquelas que decorreriam do mero desligamento por decisão do empregador. É importante, por isso, assegurar a credibilidade de tais planos, a fim de preservar a sua função protetiva e de não desestimular o seu uso. 7. Provimento do recurso extraordinário. Afirmação, em repercussão geral, da seguinte tese: 'A transação extrajudicial que importa rescisão do contrato de trabalho, em razão de adesão voluntária do empregado a plano de dispensa incentivada, enseja quitação ampla e irrestrita de todas as parcelas objeto do contrato de emprego, caso essa condição tenha constado expressamente do acordo coletivo que aprovou o plano, bem como dos 
demais instrumentos celebrados com o empregado'(STF, Pleno, RE 590.415/SC, Rel. Min. Roberto Barroso, DJe 29.05.2015).

No mesmo sentido, decidiu o Ministro Relator Teori Zavaski no julgamento do Recurso Extraordinário no $895.759 / \mathrm{PE}$, reconhecendo a possibilidade de supressão das horas in itinere por meio de acordo coletivo de trabalho: “1. Trata-se de recurso extraordinário interposto em reclamação trabalhista
visando, no que importa ao presente recurso, à condenação da reclamada
ao pagamento de 4 (quatro) horas in itinere, com os reflexos legais. O
Tribunal Superior do Trabalho decidiu a controvérsia nos termos da
seguinte ementa (fl. 1, doc. 29):
RECURSO DE EMBARGOS INTERPOSTO SOB A ÉGIDE DA LEI N.
$11.496 / 2007$. HORAS IN ITINERE. SUPRESSÃO. NORMA COLETIVA.
INVALIDADE.
1. O princípio do reconhecimento das convenções e acordos coletivos de
trabalho, consagrado no artigo $7^{\circ}$, XXVI, da Constituição da República,
apenas guarda pertinência com aquelas hipóteses em que o conteúdo das
normas pactuadas não se revela contrário a preceitos legais de caráter
cogente.
(...)
O Tribunal de origem entendeu, todavia, pela invalidade do acordo
coletivo de trabalho, uma vez que o direito às horas in itinere seria
indisponível em razão do que dispõe o art. $58, \S 2^{\circ}$, da CLT:

(...)

Registre-se que a própria Constituição Federal admite que as normas coletivas de trabalho disponham sobre salário (art. $7^{\circ}, \mathrm{VI}$ ) e jornada de trabalho (art. $7^{\circ}$, XIII e XIV), inclusive reduzindo temporariamente remuneração e fixando jornada diversa da constitucionalmente estabelecida. Não se constata, por outro lado, que o acordo coletivo em questão tenha extrapolado os limites da razoabilidade, uma vez que, embora tenha limitado direito legalmente previsto, concedeu outras vantagens em seu lugar, por meio de manifestação de vontade válida da entidade sindical.

4. Registre-se que o requisito da repercussão geral está atendido em face do que prescreve o art. 543-A, § 3º do CPC/1973: "Haverá repercussão geral sempre que o recurso impugnar decisão contrária a súmula ou jurisprudência dominante do Tribunal".

5. Diante do exposto, com base no art. 557, $\S 1^{\circ}$-A, do CPC/1973, dou provimento ao recurso extraordinário para afastar a condenação da recorrente ao pagamento das horas in itinere e dos respectivos reflexos salariais. Após o trânsito em julgado, oficie-se à Vice-Presidência do Tribunal Superior do Trabalho, encaminhando-lhe cópia desta decisão para as devidas providências, tendo em conta a indicação do presente apelo como representativo de controvérsia (STF, RE 895.759/PE, Rel. Min. Teori Zavascki, decisão monocrática, DJe 13.09.2016).

No entanto, como é próprio da lenta construção jurisprudencial, o Pleno do Tribunal Superior do Trabalho, no julgamento do Recurso de Revista $n^{0}$ 20590057.2007.5.09.0325, decidiu, naquele caso concreto, que a natureza salarial das horas in itineri não poderia ser afastada mediante acordo coletivo, por se tratar de hipótese 
distinta daquela anteriormente julgada pelo STF no Recurso Extraordinário $\mathrm{n}^{\circ}$ 895.759/PE.

Nota-se, assim a importância do fortalecimento das discussões processuais envolvendo os Direitos Fundamentais Trabalhistas, como alternativa viável no presente cenário de desconstrução do Direito do Trabalho. A dinâmica do mundo do trabalho e dos atores sociais exige justamente discussões que possam ser consideradas democráticas e permanentes em busca de soluções que pareçam adequadas àquela comunidade de praticantes da Constituição.

Evidentemente, não se trata de considerar que, entre jurisdição e legislação, a primeira ou a segunda podem, definitivamente, contemplar melhores soluções para as demandas dos cidadãos por respeito e consideração. Todavia, as divergências jurisprudenciais, que advém dos julgamentos de incontáveis casos concretos e suas peculiaridades, revelam que uma reforma trabalhista que simplesmente veja na autonomia negocial uma espécie de soberania da negociação, encontra-se na contramão do primado da proteção fundamental devida às pessoas que necessitam viver do seu trabalho.

É certo que a conceituação do que sejam direitos fundamentais é particularmente difícil, tendo em vista a sua ampliação e a transformação no percurso acidentado da história. Aumenta essa dificuldade o fato de se empregarem várias expressões para designá-los, como "direitos naturais", "direitos humanos", "direitos públicos subjetivos", "liberdades fundamentais" 4 etc. A diversidade do uso da linguagem certamente está relacionada à complexidade da aliança entre o conceitual jurídico e a vivência das pessoas concretas.

A expressão direitos fundamentais, porém, consoante assinala José Afonso da Silva (2005, p. 56), não significa esfera privada contraposta à atividade pública, mas, sim, "limitação imposta pela soberania popular aos poderes constituídos do

4 Consoante assinala Virgílio Afonso da Silva (2005, p. 55) a expressão direitos naturais refere-se "àqueles inerentes à natureza do homem; direito inatos que cabem ao homem só pelo fato de ser homem". Já direitos humanos é a expressão preferida nos documentos internacionais, sendo terminologia pouco usada na doutrina, salvo para referir-se aos direitos civis ou liberdades civis. Os direitos públicos subjetivos constituem "um conceito técnico-jurídico do Estado Liberal, preso, como a concepção direitos individuais, à concepção individualista do homem (SILVA, 2005, p. 55). Liberdades fundamentais ou liberdades públicas são expressões ligadas à concepção dos direitos públicos subjetivos e direitos individuais". 
Estado que dela dependem". Da definição exposta pelo autor, verifica-se sua posição no sentido de limitar a expressão ao campo de abrangência da proteção dos particulares em contraposição ao Estado.

Uma noção mais atualizada dos direitos fundamentais, por seu turno, conduz à conclusão de que estes representam a constitucionalização dos direitos humanos que gozaram de alto grau de justificação ao longo da história e que são reconhecidos como condição para o exercício dos demais direitos. Haveria, dessa forma, "um conteúdo mínimo de direitos fundamentais que caracterizam o direito de um Estado Democrático" (SAMPAIO, 2006, p. 17).

No entanto, como se empreender a interpretação dos Direitos Fundamentais Trabalhistas? Pode-se afirmar que a interpretação constitucional é concretização. O procedimento de concretização proposto por Hesse (1998, p. 63) prevê que no avanço tópico, guiado e limitado normativamente, devem ser achados e demonstrados pontos de vista dirigentes que são buscados e fundamentam a decisão final da maneira mais convincente possível. Se esses pontos de vista contêm premissas materialmente apropriadas, elas possibilitam deduções que conduzem ou contribuem para a resolução de problemas. O intérprete, então, deve escolher os pontos de vista - topoi - apropriados, excluindo os demais.

Hesse (1992, p. 45) refere que aos princípios de interpretação constitucional corresponde a missão de orientar o processo de interpretação. Dentre esses princípios, o autor ressalta o da força normativa da constituição, que pugna que se dê preferência à solução dos problemas jurídico-constitucionais que conduzam à máxima efetividade da norma constitucional. De acordo com o princípio da máxima efetividade, o intérprete constitucional deve ter compromisso com a efetividade da constituição de forma que, entre interpretações possíveis, deverá preferir aquela que permita a atuação da vontade constitucional, evitando-se ao máximo soluções que elidam a sua incidência .

Desta forma, somente a análise das normas coletivas à luz da constituição (ou sob sua melhor luz) é que permitirá a adequada solução jurídica das lides trabalhistas que se apresentarem a partir do cotejo das normas coletivas com a legislação pátria.

Por isso, reformas trabalhistas que atuem em direção à flexibilização de direitos, com significado de redução, não podem ter o condão de derrogar a 
Constituição e devem ser lidas e criticamente analisadas a partir do que ela (a Constituição) constitui, ou seja, uma comunidade de cidadãos que se reconhecem reciprocamente como iguais, não podendo o trabalhador e sua cidadania ser encarado como mero instrumento utilitário para o custo (maior ou menor) da produção econômica.

\section{Considerações Finais}

Após as análises empreendidas no presente artigo, chega-se à conclusão de que a prevalência ou não da negociação coletiva sobre as normas legisladas deve ser fruto da análise jurisprudencial centrada na peculiaridade de cada caso, no qual é possível visualizar a tensão existente entre direitos fundamentais demandados pelos atores do mundo do trabalho. Não se trata de escolher a jurisdição como melhor forma de manifestação dos direitos, mas, sim, de considerar que essa importante função do sistema não pode ser bloqueada por uma reforma trabalhista que aprioristicamente defina a soberania da negociação.

O que está em jogo é o primado da Constituição naquilo que ela pode representar como compromisso de realização dos direitos fundamentais. O trabalho, como manifestação da cidadania, não pode ser encarado como mero evento econômico.

$\mathrm{O}$ que define a proteção às pessoas que necessitam viver do seu trabalho igualmente não é o fator econômico de hipossuficiência, mas uma análise crítica das estruturas institucionais que estão envolvidas no complexo mundo do trabalho. Dentre essas estruturas formais, os sindicatos aparecem de forma importante. Ainda que se deva prestigiar e privilegiar as soluções coletivas, não se pode considerar viável que haja, como uma fórmula fechada, a prevalência do negociado sobre o legislado, ainda mais quando esteja em jogo normas constitucionalmente estabelecidas. Acrescente-se a isso o problema que já se reconhece presente na estrutural sindical rígida que tem sobrevivido no tempo e com nefastos efeitos para o coletivo dos trabalhadores.

A Constituição, sem dúvida, é práxis, e não apenas um texto, e é da primeira (a práxis) que depende os traços de um percurso que pode apontar para o futuro. Aliás, qual é o futuro do Direito do Trabalho no Brasil? Seria ele mero instrumento de força 
a legitimar a redução da cidadania? Ou um Direito realmente autônomo que tem no seu eixo a pessoa humana?

Com efeito, conforme visto no presente artigo, o trabalho é elemento de construção da cidadania e não há como este complexo feixe de relações jurídicas trabalhistas, que é essencial à consolidação do Estado Democrático Social de Direito, ser desestruturado de forma unilateral e sem discussão com a sociedade e seus diversos e plurais atores.

\section{REFERÊNCIAS BIBLIOGRÁFICAS}

ARENDT, Hannah. "Labor, trabajo, acción. Una conferencia". In: De la historia a la acción. Barcelona : Editorial Paidós, 1995, p. 89-107.

BRASIL. Constituição Federal de 1988. Disponível em

<http://www.planalto.gov.br/ccivil_03/constituicao/constituição.htm>. Acesso em: $10 / 02 / 2017$

Decreto-lei n. ${ }^{\circ}$ 5.452, de 1de maio de 1943. Aprovada a consolidação das leis do trabalho. Disponível em:< http://www.planalto.gov.br/ccivil_03/decretolei/Del5452.htm>. Acesso em:11/02/2017.

. Supremo Tribunal Federal. Recurso Extraordinário 895.759

Pernambuco. Disponível em:<

http://www.stf.jus.br/portal/jurisprudencia/listarJurisprudencia.asp?s1=\%28RE\%24\% 2ESCLA\%2E+E+895759\%2ENUME\%2E\%29+NAO+S\%2EPRES\%2E\&base=base Monocraticas\&url=http://tinyurl.com/okagalc>. Acesso em: 06/04/2017

Supremo Tribunal Federal. Recurso Extraordinário 590.415 Santa

Catarina. Disponível em:<

http://www.stf.jus.br/portal/jurisprudencia/listarJurisprudencia.asp?s1=\%28RE\%24\% 2ESCLA\%2E+E+590415\%2ENUME\%2E\%29+OU+\%28RE\%2EACMS\%2E+ADJ2 $+590415 \%$ 2EACMS\%2E\%29\&base=baseAcordaos\&url=http://tinyurl.com/bjs4w94> . Acesso em: 05/04/2017.

. Tribunal Superior do Trabalho. Recurso de Revista $\mathbf{n}^{0}$ 205900-

57.2007.5.09.0325. Disponível em:<

http://www.migalhas.com.br/Quentes/17,MI246278,101048-

TST+Acordo+coletivo+de+horas+in+itinere+sem+contrapartida+e+invalido>.

Acesso:10/04/2017.

. Câmara dos Deputados. Projeto de Lei 4962/2016. Disponível em:<

http://www.camara.gov.br/proposicoesWeb/fichadetramitacao?idProposicao $=208178$ 2>. Acesso em: 08/03/2017.

. Câmara dos Deputados. Projeto de Lei 6797/2016. Disponível em:< http://www.camara.gov.br/proposicoesWeb/prop_mostrarintegra;jsessionid=0853905 D6F903F493EB297075FAFBD03.proposicoesWebExterno1?codteor=1536399\&filen 
ame $=$ Tramitacao-EMC+579/2017+PL678716+\%3D\%3E+PL+6787/2016> . Acesso em: 10/03/2017.

CAILLÉ, Alain. Nem holismo nem individualismo metodológicos: Marcel Mauss e o paradigma da dádiva. In: Rev. bras. Ci. Soc., São Paulo, v. 13, n. 38, Out. 1998. Disponível em: http://www.scielo.br/scielo.php?script=sci_arttext\&pid=S010269091998000300001\&lng=en\&nrm=iso. Acesso em 09 de novembro de 2014.

CARDOSO DE OLIVEIRA, Luís Roberto. Direito legal e insulto moral: dilemas da cidadania no Brasil, Quebec e EUA. Rio de Janeiro: Rgaramond, 2. ed., 2011.

CARVALHO NETTO, Menelick. "A Hermenêutica Constitucional e os desafios postos aos direitos fundamentais". In: LEITE SAMPAIO, José Adércio (Org.).

Jurisdição Constitucional e Direitos Fundamentais. Belo Horizonte: Del Rey, 2003a. p.141-161. . “Apresentação". In: ROSENFELD, Michel. A

identidade do sujeito constitucional. Trad. de Menelick de Carvalho Netto. Revisão Técnica Maria Fernanda Salcedo Repolês. Colaboração Guilherme Scotti e Fernando Gomes. Belo Horizonte: Mandamentos, 2003.Belo Horizonte: Mandamentos, 2003b.

DELGADO, Maurício Godinho. Curso de Direito do Trabalho. $15^{\text {a }}$ ed. São Paulo: LTr, 2016.

FELICIANO, Guilherme Guimarães. Liberdade Sindical: a quantas anda no Brasil?. Disponível em:< https://www.anamatra.org.br/artigos/25007-liberdadesindical-a-quantas-anda-no-brasil> . . Acesso em 16/03/2017.

FIGUEIRA, Luiz Eduardo \& MENDES, Regina Lúcia Teixeira. "Hipossuficiência: mapeamento dos sentidos da categoria no campo jurídico brasileiro". In: Pensando bem: estudos de sociologia e antropologia da moral. Alexandre Werneck ... [et al.]. Organização Alexandre Werneck, Luís Roberto Cardoso de Oliveira. 1. ed., Rio de Janeiro: Casa da Palavra, 2014, p. 523-535.

HESSE, Konrad. Escritos de Direito Constitucional. 2.ed. Madrid: Centro de Estúdios Constitucionales, 1992.

GEERTZ, Clifford. O saber local: novos ensaios em antropologia interpretativa. Trad. de Vera Joscelyne. 12 ed., Petrópolis, RJ: Vozes, 2012.

HESSE, Konrad. Elementos de direito constitucional da república federativa da Alemanha. Tradução Luís Afonso Heck. 20. ed. Porto Alegre: SAFE, 1998.

MARGALIT, Avishai. "Recognition II: recognizing the brother and the other". In: Aristotelian Society Supplementary, v. 75, 2001, p. 127-139.

ROSENFELD, Michel. A identidade do sujeito constitucional. Trad. de Menelick de Carvalho Netto. Revisão Técnica Maria Fernanda Salcedo Repolês. Colaboração Guilherme Scotti e Fernando Gomes. Belo Horizonte: Mandamentos, 2003.

SAMPAIO, Marília de Ávila e Silva. Aplicação dos direitos fundamentais nas relações entre particulares e a boa-fé objetiva. Rio de Janeiro: Lumen Juris, 2005. 
SILVA, José Afonso da . Aplicabilidade das normas constitucionais. 3.ed. São Paulo: Malheiros, 1998.

$$
\text { . Comentário contextual à Constituição. São Paulo: RT , } 2005 .
$$

SOUZA, Jessé. Os batalhadores brasileiros: nova classe média ou nova classe trabalhadora? Colaboradores Brand Arenari ... [et al.], Belo Horizonte: Editora UFMG, 2010.

TRINDADE, Rodrigo. Conveniência, legitimidade e oportunidade da reforma trabalhista. Disponível em:< https://www.anamatra.org.br/artigos/25077conveniencia-legitimidade-e-oportunidade-da-reforma-trabalhista $>$. Acesso em: 20/03/2017. 